\title{
Withdrawal and limitation of life support in paediatric intensive care
}

\author{
A Y T Goh, L C S Lum, P W K Chan, F Bakar, B O Chong
}

\begin{abstract}
Objectives-To compare the modes of death and factors leading to withdrawal or limitation of life support in a paediatric intensive care unit (PICU) in a developing country.

Methods-Retrospective analysis of all children ( $<12$ years) dying in the PICU from January 1995 to December 1995 and January 1997 to June $1998(n=148)$.

Results-The main mode of death was by limitation of treatment in 68 of 148 patients, failure of active treatment including cardiopulmonary resuscitation in 61 , brain death in 12 , and withdrawal of life support with removal of endotracheal tube in seven. There was no significant variation in the proportion of limitation of treatment, failure of active treatment, and brain death between the two periods; however, there was an increase in withdrawal of life support from $0 \%$ in 1995 to $8 \%$ in 1997-98. Justification for limitation was based predominantly on expectation of imminent death ( 71 of 75$)$. Ethnic variability was noted among the 14 of 21 patients who refused withdrawal. Discussions for care restrictions were initiated almost exclusively by paediatricians (70 of $75)$. Diagnostic uncertainty (36\% $v 4.6 \%)$ and presentation as an acute illness were associated with the use of active treatment.

Conclusions-Limitation of treatment is the most common mode of death in a developing country's PICU and active withdrawal is still not widely practised. Paediatricians in developing countries are becoming more proactive in managing death and dying but have to consider sociocultural and religious factors when making such decisions.

(Arch Dis Child 1999;80:424-428)
\end{abstract}

Keywords: limitation of life support; intensive care; cross cultural ethical issues

Paediatric Intensive Care Unit, University Malaya Medical Centre, 50603 Kuala Lumpur, Malaysia A Y T Goh

L C S Lum

P W K Chan

F Bakar

B O Chong

Correspondence to: Dr Goh.

Accepted 6 January 1999
Young doctors schooled in Western medicine are trained to understand that, at times, death should not be postponed and life sustaining treatment should be withdrawn. The importance of such issues has led the ethics advisory committee of the Royal College of Paediatrics and Child Health (EAC-RCPCH) to produce guidelines on the withholding and withdrawing of life saving treatment in children.

Little is known about life sustaining interventions and withdrawal in countries with a different sociocultural background. Malaysia is such a country, with a multiracial and religious population made up of Malays who are Muslims, Chinese with a blend of Taoism, Confucianism, Buddhism, and Catholicism, and Indians who are Hindus. The ethical principles that Europeans and Americans practice may appear to be inappropriate to people from other societies. ${ }^{8}$ As a result of immigration from different countries and cultures, physicians in nations like the UK,,${ }^{10}$ where there are over 1.5 million Muslims, are increasingly confronted with cross cultural ethical issues in medical decision making. We hypothesise that decisions to withdraw and limit life support are influenced by cross cultural and religious factors and that there is a changing trend, with more frequent use of care restrictions in the paediatric intensive care unit (PICU) over the years. To test this hypothesis we reviewed the modes of death based on the $\mathrm{RCPCH}$ guidelines in a single tertiary affiliated multidisciplinary PICU over two time intervals.

Methods

The University Malaya Medical Centre encompasses a six bedded multidisciplinary PICU with an average admission of 330 children each year. The paediatric department has 116 non-intensive care beds, serves a local population of 2.1 million, and forms a tertiary referral centre for the nation. The PICU mainly admits critically ill children beyond the neonatal period. Outborn term neonates with cardiorespiratory and surgical diagnoses are also admitted, whereas neonatal problems related to prematurity are admitted to a separate neonatal ICU. Postoperative cardiac cases are also admitted to a separate cardiac ICU. The PICU is staffed by one intensivist and has 24 hour physician coverage. Malaysia is a developing country with a population of 20 million. ${ }^{11}$ The predominant ethnic race consists of Malays who are Muslims; followed by Chinese who practice Taoism, Confucianism, and Buddhism; and Indians who are Hindus. A large proportion of Chinese and Indians also practice Catholicism and other forms of Christianity.

We carried out a retrospective chart review of all patients dying in the PICU over two time 


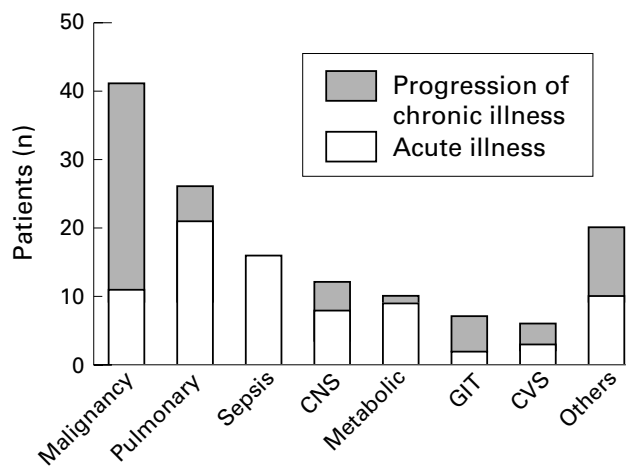

Figure 1 Diagnoses at admission to paediatric intensive care unit. CNS, central nervous system; GIT, gastrointestinal tract; CVS, cardiovascular system.

periods, from 1 January 1995 to 31 December 1995 and 1 January 1997 to 30 June 1998. Demographic data including age, race, religion, diagnosis at admittance, presence of appreciable chronic disease, presence of diagnostic uncertainty, pre-PICU cardiac resuscitation status, and time from admission until death were noted. Patients who were transferred out and died outside the PICU were excluded. We categorised admission diagnoses as follows: (1) acute illness unrelated to any chronic disease, and (2) chronic illness including natural progression or known complications of a chronic disease (for example, sepsis in oncological patients). Chronic disease was defined as health conditions that had existed for more than 30 days, thus excluding neonates. ${ }^{12}$ Diagnostic uncertainty was classified as the presence of an unresolved medical diagnosis or when the diagnosis was not known for certain at the time of death.

The mode of death was determined from documentation in the paediatric and nursing progress notes. Each death was assigned to one of the following four categories: brain death; active withdrawal of life support; death despite full active treatment, including cardiopulmonary resuscitation; and death with limitation and no further escalation of treatment and no cardiopulmonary resuscitation. We defined active withdrawal of life support as cessation of mechanical ventilation and removal of the endotracheal tube. Brain death is medically and legally accepted in Malaysia and was determined by the accepted criteria. ${ }^{13} \mathrm{Al}-$ though brain dead patients were extubated, they were not included in the active withdrawal of support category. Limitation of treatment was defined as the absence of further escalation of treatment and cardiac resuscitation should an indication for them arise. On the other hand, active treatment was the use of all available modalities of treatment, including cardiopulmonary resuscitation, which in turn was defined by institution of chest compressions and/or the use of intravenous or intratracheal dose(s) of adrenaline in an effort to restore cardiac rhythm and blood pressure.

Justifications for limitation and withdrawal of interventions were adapted from the EACRCPCH guidelines, ${ }^{7}$ which were as follows: the permanent vegetative state; the "no chance" situation where there is expectation of imminent death despite aggressive treatment; the "no purpose" situation where there is a decrease in quality of life despite potentially extended survival; and the "unbearable" situation where in the face of progressive illness further treatment is more than can be borne. The categorisation was made by both analysis of actual written opinions and retrospective reading of the medical records by the authors. The principal authors (AYT and LCS) were the paediatricians in charge of the PICU during our study period, making assessments easier to interpret. More than one rationale could apply to each patient. The process of decision making was noted by documentation of who initiated discussion for limitation and the presence of nurses, surrogates, and extended family members during these discussions.

Descriptive data are reported as mean (SD). We investigated differences in proportions of patients using $\chi^{2}$ analysis. We used nonparametric methods using the Kruskal-Wallis analysis of variance for comparisons among the modes of deaths. We considered a $p$ value $<0.05$ to be significant.

\section{Results}

There were 755 admissions to the PICU with 148 deaths identified, giving an overall mortality rate of $19.6 \%$. The mortality rate was similar over the two time intervals $(17.8 \%$ (50 of 280 ) $v 20 \%$ (98 of 475 ) for the earlier and later time periods, respectively; $p=0.23$ ). All patients initially received aggressive supportive care including mechanical ventilation, except for three patients (one each with arthrogryphosis multiplex, Patau's syndrome, and recurrent brain neoplasm) who did not undergo

Table 1 Characteristics of patients with active treatment and care restrictions

\begin{tabular}{|c|c|c|c|c|c|c|}
\hline & Number $(n=148)$ & Active treatment $(n=61)$ & Limitation $(n=68)$ & Withdrawal $(n=7)$ & Brain death $(n=12)$ & $p$ Value \\
\hline Age (months) (mean (SD)) & $39.7(46)$ & $40.8(46)$ & $35.8(44)$ & $8.7(17.9)$ & $73.2(53.4)$ & $0.002^{\star}$ \\
\hline Malay:Chinese:Indian ratio & $78: 41: 23$ & $34: 17: 7$ & $41: 16: 8$ & $2: 3: 2$ & $1: 5: 6$ & 0.09 \\
\hline Boys & $88(60)$ & 31 & 43 & 4 & 11 & 0.23 \\
\hline Chronic illness & $69(47)$ & 24 & 40 & 2 & 3 & 0.06 \\
\hline Chromosomal anomaly & $12(8)$ & 7 & 5 & 0 & 0 & 0.40 \\
\hline Presenting as acute illness & $90(60)$ & 43 & 34 & 5 & 8 & $0.01+$ \\
\hline Pre-PICU CPR & $38(25)$ & 14 & 11 & 1 & 12 & $0.002^{\star}$ \\
\hline Diagnostic uncertainty & $26(18)$ & 22 & 4 & 0 & 0 & $0.0000 t$ \\
\hline Iatrogenic complications & $7(5)$ & 5 & 2 & 0 & 0 & 0.19 \\
\hline PICU LOS (days) (mean (SD)) & $6.2(8.4)$ & $4.6(9.3)$ & $7.6(7.9)$ & $7.8(9.1)$ & $5.2(3.1)$ & $0.05 \dagger$ \\
\hline CVS dysfunction & $68(43)$ & 28 & 32 & 3 & 1 & 0.07 \\
\hline CNS dysfunction & $37(25)$ & 9 & 15 & 2 & 11 & $0.004^{\star}$ \\
\hline
\end{tabular}

Values are $\mathrm{n}(\%)$ unless otherwise stated

${ }^{\star}$ Between brain death and other categories; tbetween active treatment and other categories.

CNS, central nervous system; CPR, cardiopulmonary resuscitation; CVS, cardiovascular system; LOS, length of stay; PICU, paediatric intensive care unit. 


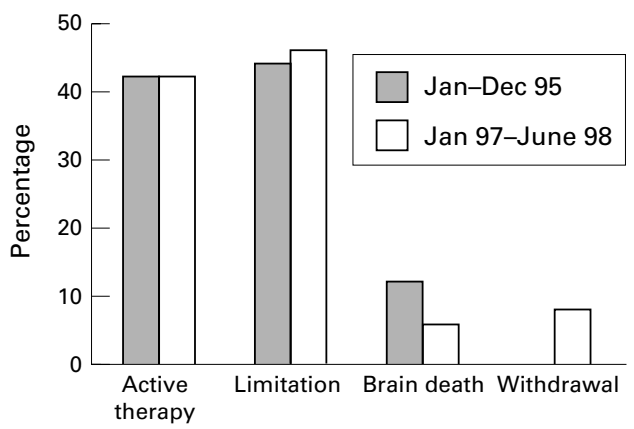

Figure 2 Variation in modes of death over two time intervals in the paediatric intensive care unit, University Malaya Medical Centre.

endotracheal intubation. Neonates ( $<28$ days) comprised $26 \%$ of the patients, $44 \%$ were infants, and $70 \%$ were aged $<4$ years. The boy: girl ratio was 1.3:1. Surgical patients constituted only $5 \%$ of the population and only one patient was a postoperative cardiac case. The median duration from admission to death was 3 days (range, 1-67 days). There were 78 Malays $(52.7 \%), 41$ Chinese $(27.7 \%), 23$ Indians $(15.5 \%)$, and six patients from other races. The most common primary organ system of dysfunction requiring PICU admission was cardiovascular (64 patients (43.2\%)), followed by the respiratory and central nervous systems in a further $38(26 \%)$ and 37 patients $(25 \%)$, respectively. Figure 1 shows the most common diagnoses requiring PICU admission. Thirty eight patients $(25.7 \%)$ had pre-PICU cardiopulmonary resuscitation. There was no difference between the age distribution, the use of pre-PICU cardiopulmonary resuscitation, and the presence of chronic disease between the ethnic races.

MODE OF DEATH IN THE PICU

The most common mode of death was by limitation of life support (68 patients $(46 \%))$. Sixty one patients $(41 \%)$ received aggressive active treatment, including cardiopulmonary resuscitation, at the time of death. Twelve patients $(8 \%)$ were extubated after fulfilling brain death criteria. Although there were 19 patients who fulfilled brain death criteria, the parents of seven refused extubation and so a decision to limit medical treatment with a "do not resuscitate" order was written instead. Active withdrawal of support was only carried out in seven patients $(5 \%)$. There was no difference in the proportion of limitation of treatment, failure of active treatment, or brain death between the two time intervals; however, there was an increase in active withdrawal from $0 \%$ in 1995 to $8 \%$ (seven of 98 ) in 1997-98. The four groups differed in several aspects (table 1). The no chance situation, or imminent death, was the most frequently cited justification for limitation of life support in 71 of 75 patients. The no purpose situation was cited in only eight cases. The discussion for implementing limitation and withdrawal was initiated by paediatricians in 70 of 75 cases. Extended family members were almost always present during the discussions but the presence of nurses was documented in only 41 cases. Families often requested the paediatrician to do what was best for their child. The pattern of care restrictions varied between the two time intervals (fig 2). Withdrawal of life support was not offered as an option to non-brain dead patients in 1995, whereas it was actively included in 21 discussions in 1997-98. Refusal for extubation after fulfilling brain death criteria occurred in just over half of patients in 1995, compared with none in 1997-98. All refusals were by Malays. Differences in recognition and acceptance of brain death as actual death were the cited reasons for refusal. The parents of 14 of 21 patients refused withdrawal and instead opted for limitation of treatment. There was ethnic variability, with Malays refusing withdrawal in nine of 11 cases, Chinese in three of six, and Indians in two of four cases each. The reasons were unclear in most cases. Parental dissent for limitation was seen in two cases; a post-liver transplant patient whose parents eventually agreed to withdrawal and a post-encephalitis patient who continued to be ventilated.

\section{Discussion}

Our study illustrates that although care restrictions in paediatric intensive care are widely used, differences exist in the pattern of their implementation. We found that limitation of treatment was the commonest mode of death in our PICU and withdrawal of treatment was rare. Our definitions of the modes of death were comparable to those used in three recent studies. ${ }^{614} 15$ In three other studies, although the patients with limitation and withdrawal of treatment were combined, data were available in the studies to separate them into similar categories for comparison ${ }^{3-5}$ (table 2). Cumulated rates of limitation and withdrawal of treatment ranged from $30 \%$ to $65 \%$, with the rate of withdrawal of treatment with extubation varying even more, from $2 \%$ to as high as $50 \%$. Discrepancies might be the result of differences in case mixes or families and/or paediatricians' ethical attitudes. Martinot and colleagues ${ }^{6}$ and Lantos and colleagues ${ }^{4}$ have shown that those with cardiac disease or a cardiac surgical diagnosis were more likely to have active treatment at the time of death. This was not the case in our study because most of our patients were

Table 2 Comparison of different modes of death in paediatric intensive care units in different parts of the world

\begin{tabular}{llllllll}
\hline & $\begin{array}{l}\text { Kuala Lumpur } \\
\text { (Malaysia) }\end{array}$ & $\begin{array}{l}\text { Washington (USA) } \\
1992^{3}\end{array}$ & $\begin{array}{l}\text { Salt Lake (USA) } \\
1993^{14}\end{array}$ & $\begin{array}{l}\text { Chicago (USA) } \\
1993^{4}\end{array}$ & $\begin{array}{l}\text { Alberta (Canada) } \\
1993^{15}\end{array}$ & $\begin{array}{l}\text { London } \\
1996^{5}\end{array}$ & France $^{1998^{6}}$ \\
\hline Active treatment & 41 & 38 & 19 & 46 & 29 & 18 & 26 \\
Limitation/DNR & 46 & 14 & 26 & 28 & 15 & 15 & 27 \\
Withdrawal & 5 & 18 & 32 & 23 & 34 & 50 & 27 \\
Brain death & 8 & 30 & 23 & 22 & 17 & 20 \\
Overall mortality & 19 & 16 & 5 & 8 & 9 & 14 & 13 \\
\hline
\end{tabular}

DNR, do not resuscitate. 
non-cardiac. Presentation as an acute illness, diagnostic uncertainty, and presence of iatrogenic complications in our patients resulted in continued use of aggressive medical treatment. Perception of failure if the medical prognosis is not attained and fear of medical litigation in those with iatrogenic complications might have contributed to this.

The RCPCH calls for decision makers to respect the values and beliefs of the family for optimal decision making. ${ }^{7}$ Our community's lesser insistence on self determination, its lower level of Western medical knowledge, and its perception of the doctor as an authority figure has led to persistence of "paternalism with permission", ${ }^{16}$ where decision making powers are returned to the paediatrician by the family. The basic obligation should always be to act in the child's best interest. ${ }^{71} 18$ Families often readily accept paediatricians' recommendations to limit treatment yet refuse withdrawal in the face of imminent death. This dichotomy is partly explained by religious differences in interpretation of death. ${ }^{19-21}$ In Islam, death is only accepted once there is cessation of the heart and breathing, even if these are maintained merely by life support (Wadee SA. Organ transplantation and the Shari'ah (Islamic Law). Proceedings international seminar on organ transplantation and healthcare management from Islamic perspective, 29-30 July 1996). For Islamic patients, withdrawal was difficult once life support was instituted, in contrast to the RCPCH guidelines which state that parents may find it easier to withdraw after treatment is instituted, because they believe everything possible has been done. Culturally, Western medicine forms only a portion of a complex mix of influences in the decision making process. Familial harmony, responsibility, and lifetime experiences are equally important. $^{20}$

Although ethically and legally, withdrawing and limitation of treatment are considered equivalent, paediatricians might draw a distinction between the two. Similar concerns have been voiced among physicians in the $\mathrm{UK}^{22}$ and other Asian countries such as Japan. ${ }^{23}$ There has been a small but noticeable trend towards the acceptance of this axiom over the years. This evolution in practice towards a more active role in managing deaths might have been brought about by an increasing awareness of global communication and literature, increasing experience locally and overseas regarding how ethical issues are resolved. Teaching of ethics of the dying patient in the medical and nursing curricula is expected to lead to further changes in the future.

Care restrictions were often based on the no chance situation, occurring after failure of therapeutic interventions, with death following promptly after placement of such orders. The no purpose situation was perhaps more difficult for two reasons. There is uncertainty in predicting future quality of life, and what constitutes intolerable handicap also differs between individuals. ${ }^{7}$ Discussions for care restrictions were almost exclusively initiated by paediatricians. The suddenness with which children become ill and the foreignness of the PICU precludes parents from taking such initiatives. In the five who did, presence of prior chronic disease had sensitised the parents to consider the benefits versus the burden of treatment. Team involvement was seen with frequent discussion among senior doctors (LCS and AYT) and caregivers before coming to a common decision to restrict care. We were concerned, however, by the underrepresentation of nurses in these discussions, which was more common than thought previously. ${ }^{24}$ Perhaps this new document comes as a timely reminder of the need for complete team effort.

The implementation of care restrictions is greatly influenced by paediatricians' personal biases and patients' clinical, sociocultural, and religious characteristics. Dilemmas in medical ethics are expected to intensify as societies become better informed and more complex with conflicting beliefs and values. There is already a rise in requests for unreasonable treatment worldwide. ${ }^{25}$ Future directions include discourse to the courts or ethics committees in cases of parental dissent. The legal system has not yet had an impact on medical ethical decision making in Malaysia. It is within this context of change and uncertainty that the EAC-RCPCH document provides a timely framework from which to form a reasoned and compassionate approach towards care restrictions in our children. ${ }^{76}$

1 Duff RS, Campbell AGM. Moral and ethical dilemmas in he special-care nursery. $N$ Engl f Med 1973;289:890-4.

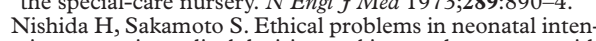
sive care unit-medical decision making on the neonate with poor prognosis. Early Hum Dev 1992;29:403-6.

3 Mink RB, Pollack MM. Resuscitation and withdrawal of therapy in paediatric intensive care. Paediatrics 1992;89: 961-3.

4 Lantos JD, Berger AC, Zucker AR. Do-not-resuscitate orders in a children's hospital. Crit Care Med 1993;21:52-

5 Balfour-Lynn IM, Tasker RC. Futility and death in paediatric medical intensive care. 7 Med Ethics 1996;22:279-81.

6 Martinot A, Grandbastien B, Leteurtre S, Duhamel A, Leclerc F. No resuscitation orders and withdrawal of therapy in French paediatric intensive care units. Acta Paetherapy in French paedia $1998 ; 87: 769-73$.

7 Royal College of Paediatrics and Child Health. Withholding or withdrawing life saving treatment in children. A framework for practice. London: RCPCH, 1997.

8 Asai A, Fukuhara S, Lo B. Attitudes of Japanese and Japanese-American physicians towards life-sustaining reatment. Lancet 1995;346:356-9.

9 Gatrad AR. Muslim customs surrounding death, bereavement, postmortem examinations, and organ transplants. $B M F$ 1994;309:521-3

10 Balarajan R, Raleigh VS. The ethnic population of England and Wales: 1991 census. Health Trends 1992;24:113-16.

1 Malaysia's Health 1996. Technical report of the DirectorGeneral of Health, Ministry of Health, Malaysia, 1996.

12 Levetown M, Pollack MM, Cuerdon TT, Ruttimann UE, Glover JJ. Limitations and withdrawal of medical intervention in paediatric critical care. $7 A M A$ 1994;272:1271-5.

13 American Academy of Paediatrics task force on brain death in children guidelines for the determination of brain death in children. Paediatrics 1987;80:298-300.

14 Vernon DD, Dean JM, Timmons OD, Banner W, AllenWebb EM. Modes of death in the paediatric intensive care unit: withdrawal and limitation of supportive care. Crit Care Med 1993;21:1798-802.

15 Ryan CA, Byrne P, Kuhn S, Tyebkhan J. No resuscitation and withdrawal of therapy in a neonatal and paediatric intensive care unit in Canada. F Paediatr 1993;123:534-8.

16 Cross AW, Churchill LR. Ethical and cultural dimensions of informed consent. Ann Intern Med 1982;96:110-13. 17 American Academy of Paediatrics. Guidelines on forgoing 532-6.

18 Nelson LJ, Nelson RM. Ethics and the provision of futile, harmful, or burdensome treatment to children. Crit Care Med 1992;20:427-33. 
19 Farrell MM, Levin DL. Brain death in the paediatric patient: historical, sociological, medical, religious, cultural, legal, and

20 Hoang GN, Erickson RV. Guidelines for providing medical care to Southeast Asian refugees. $\mathscr{A} A M A$ 1982;24 710-14.

21 Keown D, Keown J. Killing, karma and caring: euthanasia in Buddhism and Christianity. F Med Ethics 1995;21: 265-9.

22 Hatherill M, Tibby SM, Williams C, Marsh MJ, Murdoch IA. Withdrawal of ventilation from the dying child [letter]. BMF 1998;317:80.
23 Asai A, Fukuhara S, Inoshita O, Miura Y, Tanabe N, Kurokawa K. Medical decisions concerning the end of life: a discussion with Japanese physicians. F Med Ethics 1997;23:323-7

$24 \mathrm{McHafie}$ HE, Fowlie PW. Withdrawing and withholding treatment: comments on new guidelines. Arch Dis Child 1998;79:1-5.

25 Lee DK, Swinburne AJ, Fedullo AJ, Wahl GW. Withdrawing care: experience in a medical intensive care unit. $f A M A$ 1994;271:1358-61.

26 Gillis J. When life-saving treatment in children is not the answer. BMF 1997;315:1246-7. 